\title{
The Escherichia coli BarA-UvrY two-component system is a virulence determinant in the urinary tract Henrik Tomenius ${ }^{1,2}$, Anna-Karin Pernestig 2,3, Kristina Jonas ${ }^{1,2}$, Dimitris Georgellis ${ }^{4}$, Roland Möllby ${ }^{2}$, Staffan Normark ${ }^{2}$ and Öjar Melefors*1,2
}

Address: ${ }^{1}$ Swedish Institute for Infectious Disease Control, SE-17182 Solna, Sweden, ${ }^{2}$ Microbiology and Tumorbiology Center, Karolinska Institutet, SE-17177 Stockholm, Sweden, ${ }^{3}$ School of Life Sciences, University of Skövde, SE-54128 Skövde, Sweden and ${ }^{4}$ Departamento de Genética Molecular, Instituto de Fisiologia Celular, Universidad National Autónoma de México, 04510 México D.F, Mexico

Email: Henrik Tomenius - henrik.tomenius@mtc.ki.se; Anna-Karin Pernestig - anna-karin.pernestig@his.se; Kristina Jonas - kristina.jonas@smi.ki.se; Dimitris Georgellis - dimitris@ifc.unam.mx; Roland Möllby - roland.mollby@mtc.ki.se; Staffan Normark - staffan.normark@stratresearch.se; Öjar Melefors* - ojar.melefors@smi.ki.se

* Corresponding author

Published: 10 March 2006

BMC Microbiology2006, 6:27 doi:10.1186/147|-2180-6-27

This article is available from: http://www.biomedcentral.com/I47/-2/80/6/27

(C) 2006Tomenius et al; licensee BioMed Central Ltd.

This is an Open Access article distributed under the terms of the Creative Commons Attribution License (http://creativecommons.org/licenses/by/2.0), which permits unrestricted use, distribution, and reproduction in any medium, provided the original work is properly cited.

\begin{abstract}
Background: The Salmonella enterica BarA-SirA, the Erwinia carotovora ExpS-ExpA, the Vibrio cholerae BarA-VarA and the Pseudomonas spp GacS-GacA all belong to the same orthologous family of two-component systems as the Escherichia coli BarA-UvrY. In the first four species it has been demonstrated that disruption of this two-component system leads to a clear reduction in virulence of the bacteria. Our aim was to determine if the Escherichia coli BarA-UvrY two-component system is connected with virulence using a monkey cystitis model.
\end{abstract}

Results: Cystitis was generated in Macaque fascularis monkeys by infecting the bladder with a I:I mixture of the uropathogenic Escherichia coli isolate DSI 7 and a derivative where the uvrY gene had been disrupted with a kanamycin resistance gene. Urine was collected through bladder punctuation at subsequent time intervals and the relative amount of uvrY mutant was determined. This showed that inactivation of the UvrY response regulator leads to a reduced fitness. In similar competitions in culture flasks with Luria Broth (LB) the uvrY mutant rather had a higher fitness than the wild type. When the competitions were done in flasks with human urine the uvrY mutant initially had a lower fitness. This was followed by a fluctuation in the level of mutant in the long-term culture, with a pattern that was specific for the individual urines that were tested. Addition of LB to the different urine competition cultures however clearly led to a consistently higher fitness of the uvrY mutant.

Conclusion: This paper demonstrates that the BarA-UvrY two-component system is a determinant for virulence in a monkey cystitis model. The observed competition profiles strengthen our previous hypothesis that disruption of the BarA-UvrY two-component system impairs the ability of the bacteria to switch between different carbon sources. The urine in the bladder contains several different carbon sources and its composition changes over time. Inability to efficiently switch between the carbon sources may thus provide an explanation to the reduced fitness of the uvrY mutant in the cystitis model. 


\section{Background}

The rapid adjustment of bacteria to new conditions largely relies on two-component systems (TCS). In the prototypic model an environmental stimulus interacts with the $\mathrm{N}$ terminus of a sensor protein, leading to autophosphorylation of a specific histidine residue using ATP. The sensor then acts as a kinase and transmits the phosphate group to a conserved aspartate residue on a cognate response regulator protein. This normally enables the regulator to control the transcription of a certain set of genes by sequence specific DNA binding.

Sequencing of the Escherichia coli genome has identified more than 30 TCS [1]. Four Escherichia coli sensor proteins, ArcB, EvgS, TorS and BarA, have two extra domains, $\mathrm{D} 1$ and $\mathrm{H} 2$, besides the $\mathrm{H} 1$ transmitter domain and are thus denoted as 'tripartite' [2-6]. The Escherichia coli tripartite sensor BarA (bacterial a daptive response) forms a TCS with the UvrY response regulator protein $[7,8]$. UvrY positively controls expression of the noncoding $c s r B$ and $c s r C$ RNAs [9-11], which bind the $6.8 \mathrm{kD}$ CsrA protein and thus prevent it from interfering with ribosome loading of various target mRNAs [12]. The Csr (carbon storage regulation) system has been shown to have a major impact on regulation on carbon metabolism pathways [13]. Deletion of the barA or uvrY genes in Escherichia coli, as a consequence, has drastic effects on the ability of the bacteria to successfully grow in a competition depending on the carbon source of the medium [14]. Mutations in the Csr system in Escherichia coli and Salmonella enterica also cause other phenotypic effects, including changes in motility, adhesion and biofilm formation [10,15-19].

Deletions of orthologous systems in other bacteria; BarASirA in Salmonella enterica, ExpS-ExpA in Erwinia carotovora, BarA-VarA in Vibrio cholerae and GacS-GacA in Pseudomonas spp, clearly diminishes virulence of the bacteria $[20,21]$. The fact that this system is important for infections in a large spectrum of host organisms has also been corroborated by work demonstrating the necessity of the Pseudomonas GacS-GacA system for infections in either animals, nematodes, insects or plants [22]. The underlying mechanism behind this effect on virulence is far from clear. Several indirect effects have been reported, particularly on the formation of secreted molecules implied in the virulence of the bacteria [20], but the only verified direct target genes are functional homologues to the $\operatorname{csr} B /$ $c s r C$ regulatory RNAs as well as the genes encoding the HilA and HilC transcriptional regulators in Salmonella $[10,23,24]$.

The nature of a physiological stimulus acting directly on the sensor is still elusive. Bile and intestinal short fatty acids have a clear effect on this two-component system in Salmonella enterica $[25,26]$, although it is unclear if these effects are mediated via the sensor or not. Considering the fact that the system is activated in bacterial monocultures, we earlier proposed that a stimulus reflects the energy/ growth status of the cell [14].

Escherichia coli is the causative agent in more than $80 \%$ of the uncomplicated human urinary tract infections [27]. Macaque fascularis monkeys express the digalactoside receptors to which the $\mathrm{P}$ fimbriated uropathogenic Escherichia coli strains bind and thus provide a suitable animal model system to study a cystitis [27]. Here we show that a mutant in the BarA-UvrY two-component system is less fit in a competition in such a cystitis model. We propose that this effect is at least partially mediated by a reduced ability to adapt the carbon metabolism in response to the varying carbon sources in urine.

\section{Results \& discussion \\ Monkey cystitis competition assay}

Two female monkeys were inoculated in the bladder with a 1:1 mixture of the DS17 wild type and the AKP168 uvrY mutant. Urine samples were collected at day 2, 5, 7, 13 and 15 to determine the colony forming units (CFU) and the relative number of wild type and mutant bacteria. Both monkeys exhibited typical symptoms of an acute cystitis as measured by bacteruria and an increased level of leukocyte markers in the urine (Table 1). The infections were cleared naturally by day 13 from both animals (Table 1). Our analysis of the isolated samples clearly showed that the uvrY mutant AKP168 was rapidly lost in both monkeys, in comparison with the wild type DS17 (Figure 1A). On the fifth day of infection more than $95 \%$ of the isolated bacteria were wild type. We also observed a similar take-over of the wild type strain in samples collected from the vagina in these monkeys (Figure 1B). This is expected, as urine continuously contaminates the vagina. We were however unable to perform additional infections as there were no more animals available for such a study.

Table I: Leukocyte markers and CFU

\begin{tabular}{ccccc}
\hline Day & \multicolumn{2}{c}{ Leukocytes $^{\mathrm{a}}$} & \multicolumn{2}{c}{ CFU in urine (CFU/ml) } \\
\cline { 2 - 5 } & $110-7 \mathrm{~b}$ & $40-6 \mathrm{~b}$ & $110-7 \mathrm{~b}$ & $40-6^{\mathrm{b}}$ \\
\hline 2 & $1-2$ & $2-3$ & $9.5 \times 10^{4}$ & $4.6 \times 10^{5}$ \\
5 & 3 & $2-3$ & $3.2 \times 10^{5}$ & $2.7 \times 10^{5}$ \\
7 & $1-2$ & 1 & $5 \times 10^{2}$ & $2.5 \times 10^{4}$ \\
13 & $0-1$ & $0-1$ & 0 & 0 \\
15 & 0 & 0 & 0 & 0 \\
\hline
\end{tabular}

aPresence of leukocytes was determined by the ECUR-dip stick test (Boehringer-Mannheim). Color changes of grades I, 2 and 3 correspond to 10-25, approximately 75 , and approximately 500 granulocytes $/ \mathrm{ml}$, respectively.

bldentification number for the individual monkeys. 


\section{Figure 1.}
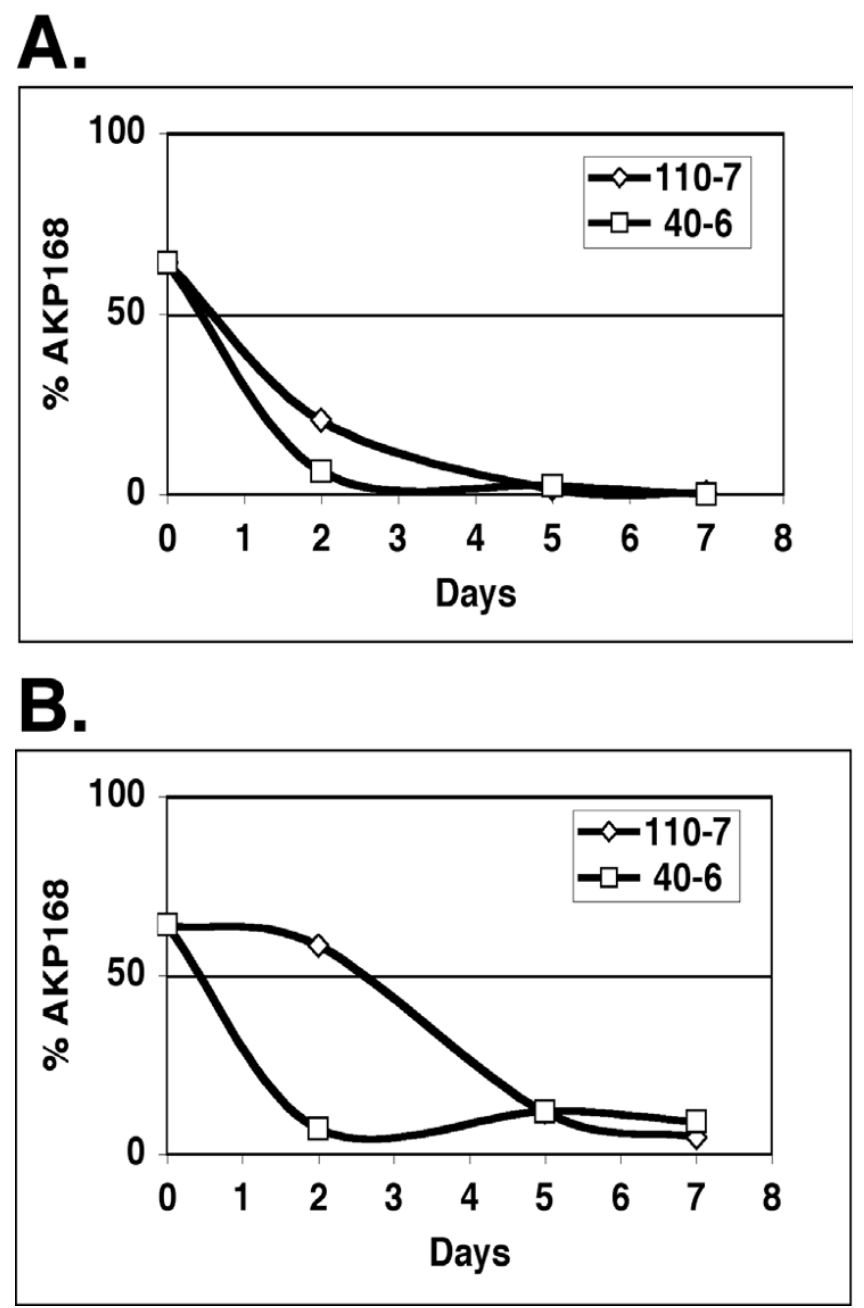

Figure I

The uvrY deletion mutant is outcompeted in the monkey bladder. A I:I mixture of DSI 7 and AKPI68 mutant was inoculated into the bladder of 2 individual monkeys (I I0-7 and 40-6) at day 0. Urine samples and vaginal smears were collected (day $2,5 \& 7$ ). The percentage of the AKP I 68 mutant was determined in $A$. urine and $B$. vaginal smears.

\section{The BarA-UvrY two-component system controls the carbon utilization in the cell}

We recently showed that the ability of a uvrY mutant to grow in a competition culture with the wild type depends on the growth medium, such that the mutant has a higher fitness than the wild type in gluconeogenic media, e.g. LB, but a lower fitness than the wild type in glycolytic media. These results led us to conclude that the BarA-UvrY TCS is important for the bacteria to efficiently switch between different carbon sources [14]. The switching ability is crucial in a glycolytic medium, as long-term growth will change the composition of the medium, with a gradual accumulation of secondary metabolites (e.g. acetate). Accumulated intermediates will in turn be metabolized when the primary metabolites are exhausted. When all carbon sources are depleted from the medium, lysed bacteria will be the only carbon source that can be used. The major carbon source in such lysates is amino acids [28]. In gluconeogenic media, based on amino acids or other small metabolites fuelling directly into the Krebs cycle, the composition of the medium will be relatively unchanged in a long-term culture, including the stage when amino acids from lysed bacteria will be the principal carbon source. Growth in such media is not directly aided by the BarA-UvrY TCS and mutants where the sensor or regulator has been disrupted are rather more fit than the wild type [14]. In support of our hypothesis, the BarA-UvrY TCS has been demonstrated to control transcription of the $\operatorname{csrB}$ and $\operatorname{csr} C$ noncoding RNAs $[9,11,29]$, which via the CsrA protein regulate the expression of genes involved in gluconeogenis and glycolysis by inversely controlling the concentration of their mRNA at the post-transcriptional level [13]. In the case of csrB, UvrY has been proven to act directly on the csrB promoter [9].

\section{Growth of wild type and uvrY mutant strains in human urine}

To test if the higher fitness of the wild type bacteria in the monkey cystitis model could be due to their ability to efficiently switch between different carbon sources present in urine we cultivated the bacteria in sterile filtered urine. The composition of urine varies between individual samples, but typically contains a mixture of amino acids, sugars and fatty acids as carbon sources [30,31].

We first cultivated the DS17 and the AKP168 strains individually in urine freshly collected from three human subjects (U1, U2 \& U3). The growth varied significantly between the individual urines but there was no significant difference in growth between the mutant and the wild type in any of the three urines (Figure 2A). We subsequently allowed the DS17 wild type and the AKP168 mutant to compete in these three human urines. Each competition culture was first split into two and the level of mutant was followed in each culture. In all six urine competitions the level of $u v r Y$ mutant decreased during the two first days, but this was followed by an increase in the level of $u v r Y$ mutant with a fluctuating pattern that was specific for each urine (Figure $2 \mathrm{~B}$ and $2 \mathrm{C}$ ). As urine is a complex medium consisting of a mixture of carbon sources, the initial decrease in the relative level of $u v r Y$ mutant may well be explained by its impaired ability to efficiently switch between gluconeogenic and glycolytic 


\section{Figure 2.}

A.
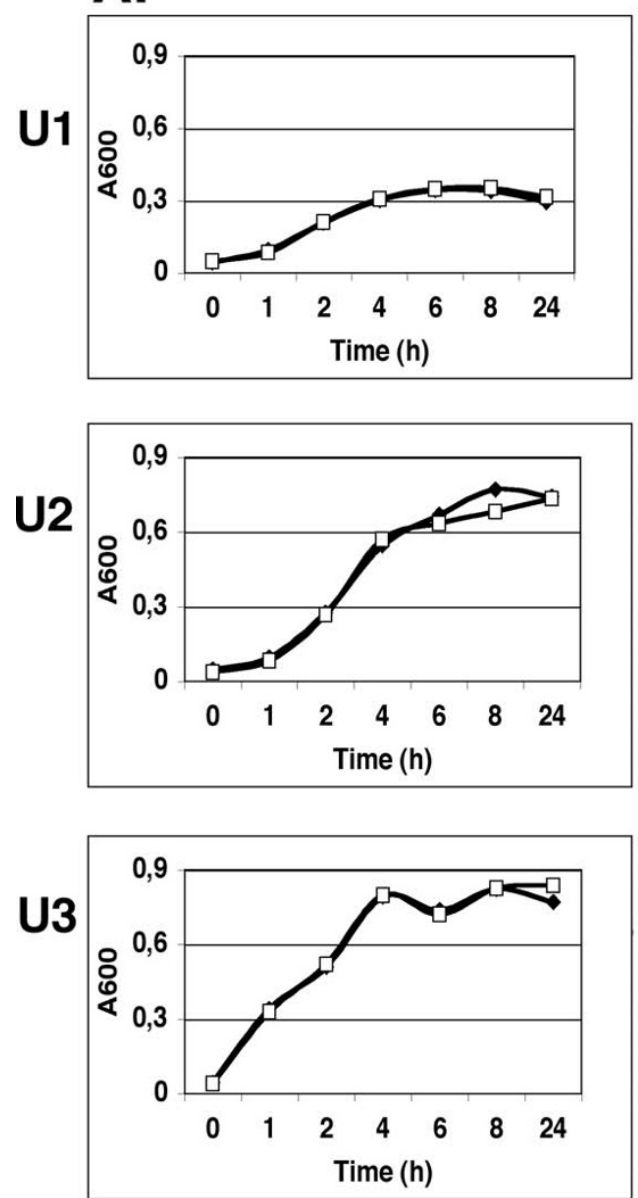

B.
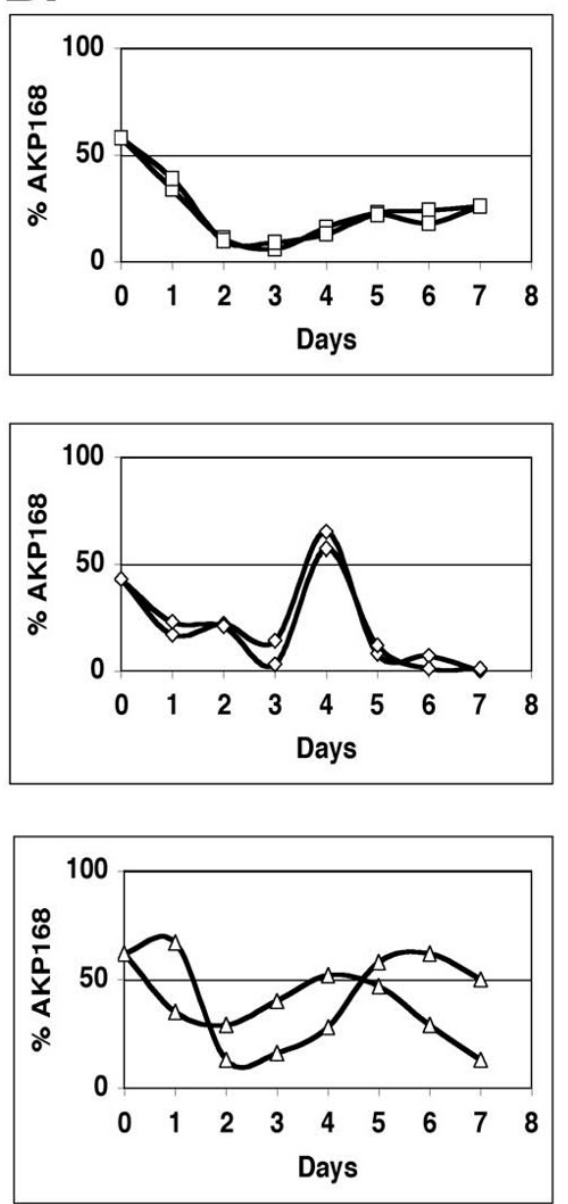

C.
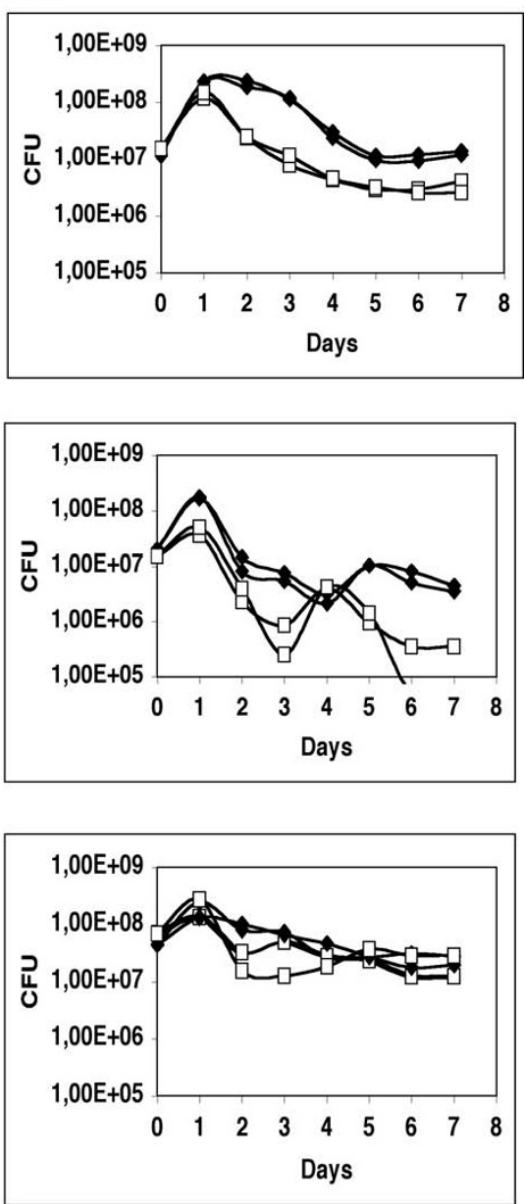

\section{Figure 2}

Growth of individual strains and In vitro competition in human urine. A. DSI 7 (filled diamonds) and AKPI 68 (squares) were grown separately in vitro in three different human urines (UI, U2 \& U3). B. I:I mixture of DSI 7 and AKPI 68 mutant was grown in the three different human urines (UI, U2 \& U3) and samples were taken at the indicated time points to determine the percentage of AKPI 68 mutant. C. The same competitions as in B. but plotted as CFU with DSI 7 depicted as filled diamonds and $A K P / 68$ as squares.

carbon sources. The competition profiles were markedly different between the urines but the same in the parallel cultures from the same urine (although with a slight time shift in U3). Our premise that the initial composition of the individual urine determines the competition profile agrees well with this reproducibility. The observed fluctuations after day 1-2 are thus unlikely to be explained by random processes or by spontaneous mutations in either the AKP168 or the wild type strain creating a growth advantage in stationary phase, GASP mutants $[32,33]$. From the results, it is more likely that each competition profile is decided by the initial composition of each individual urine. To exclude that the reduced fitness of the uvrY mutants in the urine cultures was the result of addi- tional weakening mutations, we demonstrated that mutants taken at day 7 from the different urine competitions could successfully outcompete the wild type strain in a competition in LB (Figure 3A).

The increase in the level of mutant after the initial decrease may be explained by the massive lysis of bacteria after the entry into stationary phase. Lysis will provide an environment with an excess of gluconeogenic carbon sources, where it is known that a $u v r Y$ mutant has a growth advantage [14].

We also repeated the competition in the same urines (U1, U2 \& U3) complemented with LB. In these competitions 
Figure 3.

\section{A.}
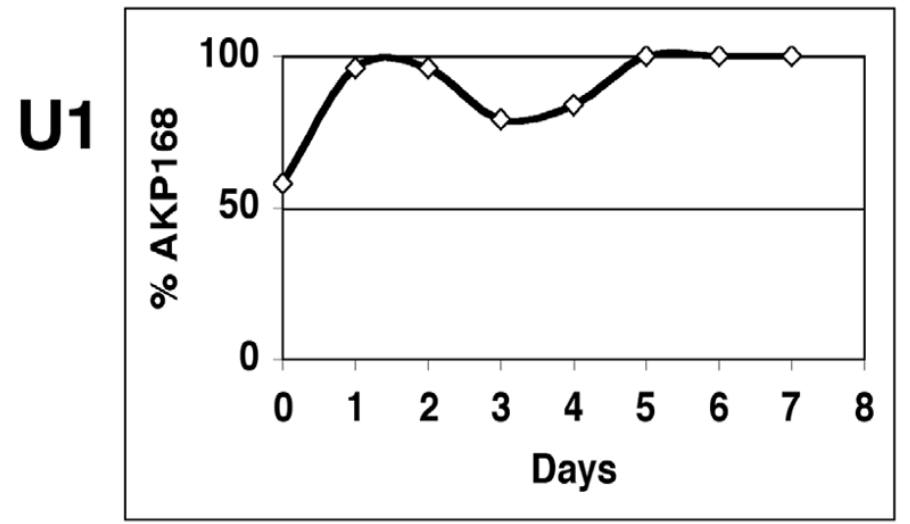

U2
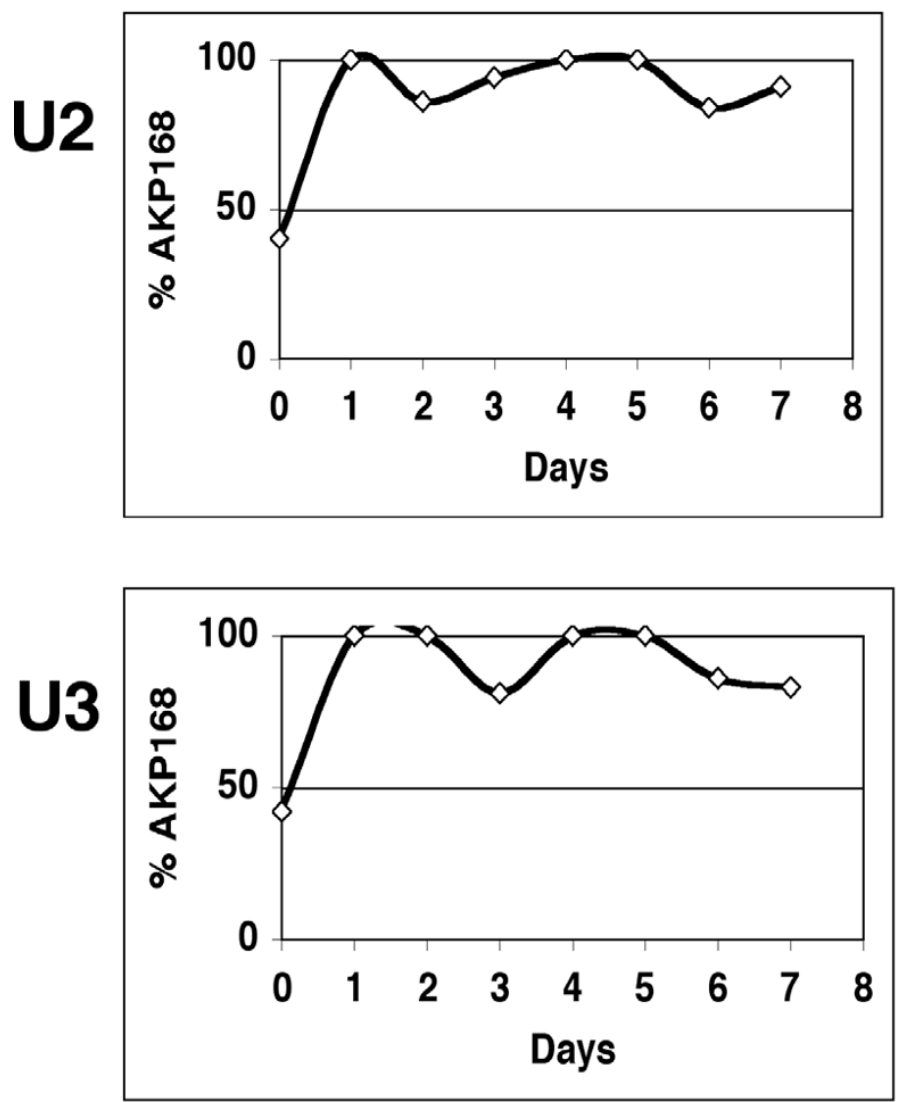

B.
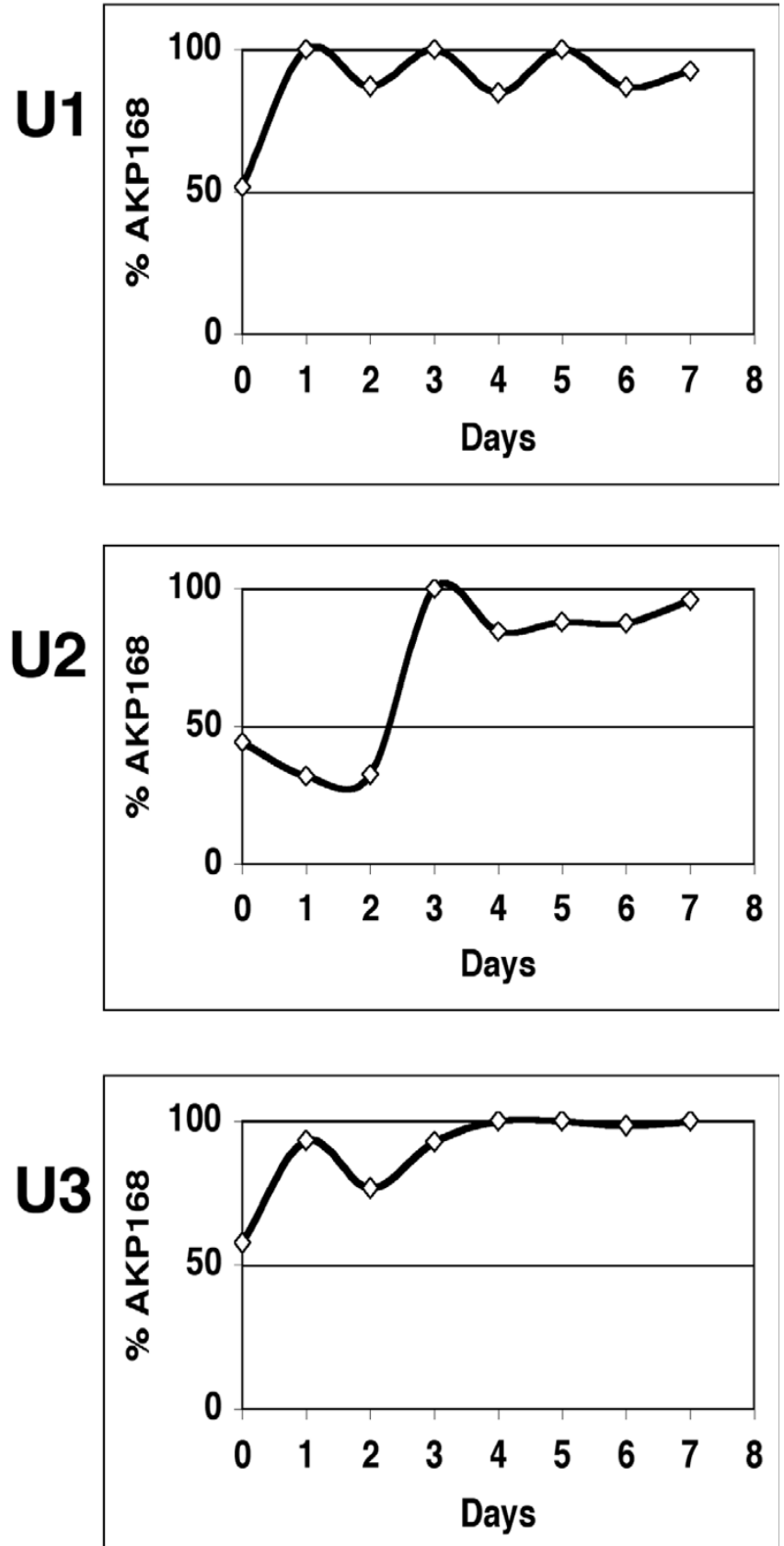

Figure 3

In vitro competition in human urine complemented with LB. A. Re-competition of uvrY mutants in LB. Three AKPI68 individual mutant clones were isolated at day seven from the urine competitions (UI, U2 \& U3) and competed against wild type DSI 7 in LB. Samples were taken at the indicated time points to determine the percentage of AKPI68 mutant. B. The same experiment as in Figure 2B but the urine was complemented with LB (see Materials \& Methods). 
where there is a constant excess of gluconeogenic carbon sources in the medium, the $u v r Y$ mutant rapidly outcompeted the wild type (Figure $3 \mathrm{~B}$ ), similar to what is observed in LB alone (Figure 3A). Thus, there seems to be no dominant factor in urine that would explain the lowered fitness of the $u v r Y$ mutant.

Although our model system cannot mimic the exact conditions in the bladder, such as the continuous addition of fresh urine, the data suggest that a $u v r Y$ mutant has an impaired ability to efficiently metabolize the different nutrient components in the urine. This also emphasizes that an optimal growth rate is critical for bacteria during an infection. In analogy with our results, it is interesting to note that long-term growth of Pseudomonas strains in gluconeogenic media selects for strains with inactivating mutations in the orthologous GacS-GacA system, unlike when the same strains are tested in an infection model (Arabidopsis) [34]. It would be interesting to test what role the described metabolic switches plays in the other bacterial species where it is known that the BarA-UvrY twocomponent system family affects virulence.

We cannot exclude that other factors under the control of this TCS contributes to the lowered fitness of the uvrY mutant observed in the in vivo cystitis model. Earlier studies have demonstrated effects of the BarA-UvrY TCS and the downstream Csr system on adhesion, aggregation and biofilm formation [10,15-19], all of which may play a role in the persistence of bacteria in the bladder in concert with the ability to utilize and switch between glycolytic and gluconeogenic carbon sources.

\section{Conclusion}

This paper demonstrates that the BarA-UvrY system is a determinant for virulence in a monkey cystitis model. Based on different competition profiles we propose that the BarA-UvrY TCS is important for the bacteria to efficiently switch between different carbon sources present in urine. This would provide a plausible explanation to the reduced fitness of the $u v r Y$ mutant in the cystitis model as urine consists of several different carbon sources and as the prevalent carbon sources will change over time. This also agrees well with the observed higher fitness of the uvrY mutant in competitions in purely gluconeogenic media as the $u v r Y$ mutant is predisposed for gluconeogenesis. In conclusion, the ability to grow quickly and benefit from the available carbon and energy sources is crucial for virulence. During infection there may be different carbon sources available and we believe that the ability to know when to metabolize them is in part conferred by the BarAUvrY two-component system.

\section{Methods \\ Monkey cystitis competition model}

Two adult female Macaque fascularis monkeys were infected by inoculation of a bacterial suspension $(1 \mathrm{ml}$ of $10^{8}$ bacteria/ml), containing equal amounts of DS17 wild type and the isogenic uvrY mutant AKP168, into the bladder using a catheter (the bladder void volume is approximately $150 \mathrm{ml}$ ). The monkeys had not been exposed to the DS17 strain earlier. Bacteria had been taken from fresh colony forming agar (CFA) plates (10 g Casamino acids, 1.5 g yeast extract, $50 \mathrm{mg} \mathrm{MgSO}_{4}, 5 \mathrm{mg} \mathrm{MnCl}, 15 \mathrm{~g}$ Bacto agar per liter) and resuspended in phosphate buffered saline (PBS). Inocula were directly analyzed on selective plates to assure that the level of mutant was close to $50 \%$. Samples from monkeys were collected by suprapubic bladder aspiration, using a syringe with vacutainer, at the time points indicated until two successive negative cultures were obtained (day 13 and day 15; Table 1). The animals were then considered healthy and removed from the study. At 20-30 min before bladder aspiration, monkeys were hydrated with approximately $50 \mathrm{ml}$ of lukewarm saline administered subcutaneously in the neck for optimal diuresis. All experiments were done under ketamine and midazolam anesthesia. Vaginal smears were collected with cotton swabs. No DS17 bacteria could be isolated from the feces of the monkeys before or after the infection. Monkeys were kept in the animal facility at the Swedish Institute for Infectious Disease Control (SMI) in $80 \times$ $70 \times 170 \mathrm{~cm}$ (width, depth, and height) cages, two in each, and were handled by professional personnel according to SMI regulations. Experiments were pre-approved by the local ethics committee in Stockholm.

\section{In vitro growth of strains}

In this work we employed the uropathogenic Escherichia coli strain DS17 [35] and the AKP168 derivative [14], with the $u v r Y$ gene disrupted by a kanamycin resistance cassette. The AKP168 mutant exhibited no measurable difference in growth relative the parental DS17 strain in a range of different media, as measured by optical density and CFU [14].

Growth was normally conducted in a $20 \mathrm{ml}$ volume in $100 \mathrm{ml}$ Erlenmeyer glass flasks at $37^{\circ} \mathrm{C}$ in a shaker with $200 \mathrm{rpm}$. Urine collected from healthy human male donors was centrifuged at $4000 \mathrm{rpm}$ and sterile filtered through a $0.45 \mu \mathrm{M}$ CA-filter (Corning Inc., NY). Urine-LB was prepared by mixing four parts of sterile filtered urine with one part of $5 \times \mathrm{LB}$ (50 g Bacto tryptone, $25 \mathrm{~g}$ Bacto yeast extract and $50 \mathrm{~g} \mathrm{NaCl}$ per liter).

In growth curve experiments each strain was grown as an over night culture in LB (10 g Bacto tryptone, $5 \mathrm{~g}$ Bacto yeast extract, $10 \mathrm{NaCl}$ per liter) started directly from a $80^{\circ} \mathrm{C}$ vial), washed twice in PBS, inoculated 1:100 in 20 
$\mathrm{ml}$ urine. $1 \mathrm{ml}$ samples were withdrawn and the optical density was measured at $600 \mathrm{~nm}$ at the indicated time points with a spectrophotometer.

In competition experiments each strain was grown as an over night culture in LB (started directly from a $-80^{\circ} \mathrm{C}$ vial), washed twice in PBS, inoculated 1:100 in urine, urine- $\mathrm{LB}$, or plain $\mathrm{LB}$, and grown as an individual culture to $A_{600}=0.15-0.30$. Subsequently, cultures were mixed $1: 1$ to a $20 \mathrm{ml}$ volume. Samples of $100 \mu \mathrm{l}$ were withdrawn at the indicated time intervals and subjected to appropriate dilution in PBS. Dilutions were added to Luria-Bertani plates, with or without kanamycin $(10 \mu \mathrm{g} / \mathrm{ml})$, together with 5 to 6 glass beads ( $6 \mathrm{~mm}$ diameter) (Stern Walter Inc, NY, USA). Plates were gently agitated for 20 seconds to evenly spread the bacteria over the plate, after which the beads were removed. The relative level of mutant was calculated by dividing the number of colonies growing on the selective plate with the number of colonies growing on the non-selective plate.

\section{Authors' contributions}

$\mathrm{HT}, \mathrm{AKP}$ and KJ carried out the experimental work. RM provided expertise for the primate experiments. All authors have been involved in the design and planning of the experiments and the drafting of the manuscript. OM coordinated the study. All authors read and approved the final manuscript.

\section{Acknowledgements}

This work was supported by grants from the Swedish Research Council. KJ has been supported by a Marie Curie Early Stage Research Training Fellowship of the European Community's Sixth Framework Programme under contract number MEST-CT-2004-8475. We thank Peter Kjäll for discussions.

\section{References}

I. Mizuno T: Compilation of all genes encoding two-component phosphotransfer signal transducers in the genome of Escherichia coli. DNA Res 1997, 4(2): 161-168.

2. Georgellis $D$, Lynch AS, Lin EC: In vitro phosphorylation study of the arc two-component signal transduction system of Escherichia coli. J Bacteriol 1997, 179(17):5429-5435.

3. Jourlin $C$, Ansaldi $M$, Mejean V: Transphosphorylation of the Tor $R$ response regulator requires the three phosphorylation sites of the TorS unorthodox sensor in Escherichia coli. J Mol Biol 1997, 267(4):770-777.

4. Tsuzuki M, Ishige K, Mizuno T: Phosphotransfer circuitry of the putative multi-signal transducer, ArcB, of Escherichia coli: in vitro studies with mutants. Mol Microbiol 1995, 1 8(5):953-962.

5. Uhl MA, Miller JF: Integration of multiple domains in a twocomponent sensor protein: the Bordetella pertussis BvgAS phosphorelay. Embo ] 1996, I5(5): 1028-1036.

6. Tomenius H, Pernestig AK, Mendez-Catala CF, Georgellis D, Normark S, Melefors O: Genetic and functional characterization of the Escherichia coli BarA-UvrY two-component system: point mutations in the HAMP linker of the BarA sensor give a dominant-negative phenotype. J Bacteriol 2005, I 87(2I):7317-7324

7. Moolenaar GF, van Sluis CA, Backendorf C, van de Putte P: Regulation of the Escherichia coli excision repair gene uvrC. Overlap between the uvrC structural gene and the region coding for a 24 kD protein. Nucleic Acids Res 1987, 15(10):4273-4289.
8. Pernestig AK, Melefors O, Georgellis D: Identification of UvrY as the cognate response regulator for the BarA sensor kinase in Escherichia coli. J Biol Chem 200I, 276(I):225-23I.

9. Suzuki K, Wang X, Weilbacher T, Pernestig AK, Melefors O, Georgellis D, Babitzke P, Romeo T: Regulatory circuitry of the CsrA/ CsrB and BarA/UvrY systems of Escherichia coli. J Bacteriol 2002, I84(I8):5|30-5|40.

10. Teplitski M, Goodier RI, Ahmer BM: Pathways leading from BarA/SirA to motility and virulence gene expression in Salmonella. J Bacteriol 2003, I85(24):7257-7265.

II. Weilbacher T, Suzuki K, Dubey AK, Wang X, Gudapaty S, Morozov I, Baker CS, Georgellis D, Babitzke P, Romeo T: A novel sRNA component of the carbon storage regulatory system of Escherichia coli. Mol Microbiol 2003, 48(3):657-670.

12. Dubey AK, Baker CS, Suzuki K, Jones AD, Pandit P, Romeo T, Babitzke P: CsrA regulates translation of the Escherichia coli carbon starvation gene, cstA, by blocking ribosome access to the cstA transcript. J Bacteriol 2003, I 85( I5):4450-4460.

13. Romeo T: Global regulation by the small RNA-binding protein CsrA and the non-coding RNA molecule CsrB. Mol Microbiol 1998, 29(6): $|32|-\mid 330$.

14. Pernestig AK, Georgellis D, Romeo T, Suzuki K, Tomenius H, Normark S, Melefors O: The Escherichia coli BarA-UvrY two-component system is needed for efficient switching between glycolytic and gluconeogenic carbon sources. J Bacteriol 2003, 185(3):843-853.

15. Agladze K, Jackson D, Romeo T: Periodicity of cell attachment patterns during Escherichia coli biofilm development. J Bacteriol 2003, 185(18):5632-5638.

16. Jackson DW, Simecka JW, Romeo T: Catabolite repression of Escherichia coli biofilm formation. J Bacteriol 2002, I84( ( 2):3406-34I0.

17. Jackson DW, Suzuki K, Oakford L, Simecka JW, Hart ME, Romeo T: Biofilm formation and dispersal under the influence of the global regulator CsrA of Escherichia coli. J Bacteriol 2002, 184(I):290-30I.

18. Wang X, Dubey AK, Suzuki K, Baker CS, Babitzke P, Romeo T: CsrA post-transcriptionally represses pgaABCD, responsible for synthesis of a biofilm polysaccharide adhesin of Escherichia coli. Mol Microbiol 2005, 56(6): I 648-I663.

19. Wei BL, Brun-Zinkernagel AM, Simecka JW, Pruss BM, Babitzke P, Romeo T: Positive regulation of motility and flhDC expression by the RNA-binding protein CsrA of Escherichia coli. Mol Microbiol 200I, 40(I):245-256.

20. Heeb S, Haas D: Regulatory roles of the GacS/GacA two-component system in plant-associated and other gram-negative bacteria. Mol Plant Microbe Interact 200I, I 4(1 2): I35 I-I 363.

21. Chan K, Kim CC, Falkow S: Microarray-based detection of Salmonella enterica serovar Typhimurium transposon mutants that cannot survive in macrophages and mice. Infect Immun 2005, 73(9):5438-5449.

22. Rahme LG, Ausubel FM, Cao H, Drenkard E, Goumnerov BC, Lau GW, Mahajan-Miklos S, Plotnikova J, Tan MW, Tsongalis J, Walendziewicz CL, Tompkins RG: Plants and animals share functionally common bacterial virulence factors. Proc Natl Acad Sci U S A 2000, 97( I6):88|5-882I.

23. Lenz DH, Miller MB, Zhu J, Kulkarni RV, Bassler BL: CsrA and three redundant small RNAs regulate quorum sensing in Vibrio cholerae. Mol Microbiol 2005, 58(4): I I 86-I 202.

24. Kay E, Dubuis C, Haas D: Three small RNAs jointly ensure secondary metabolism and biocontrol in Pseudomonas fluorescens CHAO. Proc Natl Acad Sci U S A 2005, 102:17136-17|4I.

25. Lawhon SD, Maurer R, Suyemoto M, Altier C: Intestinal shortchain fatty acids alter Salmonella typhimurium invasion gene expression and virulence through BarA/SirA. Mol Microbiol 2002, 46(5): $145 \mid-1464$.

26. Prouty AM, Gunn JS: Salmonella enterica serovar typhimurium invasion is repressed in the presence of bile. Infect Immun 2000, 68(1 2):6763-6769.

27. Warren JW: Clinical presentations and epidemiology of urinary tract ifections. In Urinary Tract Infections Molecular pathogenesis and clinical management Edited by: Mobley HLT. Washington, DC, ASM press; 1996:3-27.

28. Zinser ER, Kolter R: Mutations enhancing amino acid catabolism confer a growth advantage in stationary phase. J Bacteriol 1999, I8 I(18):5800-5807. 
29. Fortune DR, Suyemoto M, Altier C: Identification of CsrC and characterization of its role in epithelial cell invasion in Salmonella enterica serovar Typhimurium. Infect Immun 2006, 74(I):33I-339.

30. Cahill DJ, Fry $\mathrm{CH}$, Foxall PJ: Variation in urine composition in the human urinary tract: evidence of urothelial function in situ? J Urol 2003, I69(3):87|-874.

31. Gibney MJ, Walsh M, Brennan L, Roche HM, German B, van Ommen $B$ : Metabolomics in human nutrition: opportunities and challenges. Am J Clin Nutr 2005, 82(3):497-503.

32. Zambrano MM, Kolter R: GASPing for life in stationary phase. Cell 1996, 86(2): I8I-I84.

33. Zinser ER, Kolter R: Escherichia coli evolution during stationary phase. Res Microbiol 2004, I 55(5):328-336.

34. Bull CT, Duffy B, Voisard C, Defago G, Keel C, Haas D: Characterization of spontaneous gacS and gacA regulatory mutants of Pseudomonas fluorescens biocontrol strain CHAO. Antonie Van Leeuwenhoek 200I, 79(3-4):327-336.

35. Tullus K, Horlin K, Svenson SB, Kallenius G: Epidemic outbreaks of acute pyelonephritis caused by nosocomial spread of $\mathbf{P}$ fimbriated Escherichia coli in children. J Infect Dis 1984, I 50(5):728-736.

Publish with Bio Med Central and every scientist can read your work free of charge

"BioMed Central will be the most significant development for disseminating the results of biomedical research in our lifetime. "

Sir Paul Nurse, Cancer Research UK

Your research papers will be:

- available free of charge to the entire biomedical community

- peer reviewed and published immediately upon acceptance

- cited in PubMed and archived on PubMed Central

- yours - you keep the copyright

Submit your manuscript here:

http://www.biomedcentral.com/info/publishing_adv.asp
BioMedcentral 